\title{
Analyzing adaptive modulation in spinal motor neurons using multi-objective evolutionary algorithms
}

\author{
Tomasz G Smolinski ${ }^{*}$, Joseph Lombardo², Melissa A Harrington² \\ From 24th Annual Computational Neuroscience Meeting: CNS*2015 \\ Prague, Czech Republic. 18-23 July 2015
}

Spinal motoneurons have long been thought to be simply part of a relay system that provides rapid, stereotyped outputs for muscles on the basis of a supraspinal plan tuned by sensory inputs, and activity-dependent plasticity (ADP) has been presumed to be a property of the brain. However, recent work indicates that ADP occurs in spinal motor neurons during development, as well as later in life with skills acquisition and maintenance, and in response to trauma and disease [1]. Understanding how spinal motoneuron output can be modified by both increased and decreased activity is thus a fundamental challenge with implications for athletic training, rehabilitation, and advanced prosthetics. We hypothesize that that alteration in the function of Kv7.2 channel (which carries the M current) and changes in axonal initial segment (AIS) properties are the primary mechanisms of adaptation of spinal motoneurons to prolonged network activation. This hypothesis is supported by the literature and our experimental data demonstrating that persistent activation of spinal cord networks decreases spinal motoneuron output in a manner consistent with the enhancement of a sub-threshold, noninactivating potassium conductance. $\mathrm{KCNQ} / \mathrm{Kv} 7$ channels, which are non-inactivating potassium channels that activate in the sub-threshold range [2], are expressed at the AIS, nodes of Ranvier, and soma of spinal motoneurons [3,4], and modulate their excitability $[5,6]$.

To test our hypothesis, we developed a realistic computational model of spinal motoneuron activity before and after persistent network activation. As the starting point, we utilized a reconstructed spinal motoneuron morphology of neonatal mice [7] together with the

\footnotetext{
* Correspondence: tsmolinski@desu.edu

'Department of Computer and Information Sciences, Delaware State University, Dover, DE 19901, USA

Full list of author information is available at the end of the article
}

detailed specification of the active and passive somatodendritic and axonal properties derived from a rodent cortical neuron model [8]. The model parameter values were adjusted to match our recordings of motoneuron electrophysiological properties using a multi-objective evolutionary algorithm (MOEA) [9]. The algorithm matches multiple selection criteria simultaneously (e.g., spike frequency, shape, adaptation rate, etc.) and generates entire collections of neuronal models that can be mined for rules describing the phenomena captured by the models (for instance, co-regulations between ionic conductances). Furthermore, since the MOEA generates two independent databases of models (i.e., before and after persistent activation), we are able to directly compare the phenomena discovered by our data mining process in each dataset, thus elucidating the mechanisms underlying plasticity.

\section{Acknowledgements \\ Support: NIH 5P20GM103653, NIH 1R15HD075207, NSF EPSCoR 0814251, NSF HRD1242067.}

\section{Authors' details \\ 'Department of Computer and Information Sciences, Delaware State University, Dover, DE 19901, USA. ²Department of Biological Sciences, Delaware State University, Dover, DE 19901, USA.}

Published: 18 December 2015

\section{References}

1. Wolpaw JR, Tennison AM: Activity-dependent spinal cord plasticity in health and disease. Annual Review of Neuroscience 2001, 24:807-843.

2. Schroeder $\mathrm{BC}$, et al: KCNQ5, a novel potassium channel broadly expressed in brain, mediates M-type currents. J Biol Chem 2000, 275(31):24089-95.

3. Dedek K, Waldegger S: Colocalization of KCNQ1/KCNE channel subunits in the mouse gastrointestinal tract. Pflugers Arch 2001, 442(6):896-902.

4. Devaux JJ, et al: KCNQ2 is a nodal K+ channel. J Neurosci 2004, 24(5):1236-44. 
5. Alaburda A, Perrier JF, Hounsgaard J: An M-like outward current regulates the excitability of spinal motoneurones in the adult turtle. J Physiol 2002, 540(Pt 3):875-81.

6. Rivera-Arconada I, Lopez-Garcia JA: Effects of M-current modulators on the excitability of immature rat spinal sensory and motor neurones. Eur J Neurosci 2005, 22(12):3091-8.

7. Li Y, et al: Developmental changes in spinal motoneuron dendrites in neonatal mice. J Comp Neurol 2005, 483(3):304-17.

8. Kole $\mathrm{MH}$, et al: Action potential generation requires a high sodium channel density in the axon initial segment. Nat Neurosci 2008, 11(2):178-86.

9. Patel $P$, et al: Hybridization of multi-objective evolutionary algorithms and fuzzy control for automated construction, tuning, and analysis of neuronal models. BMC Neurosci 2013, 14(Suppl 1):P369.

doi:10.1186/1471-2202-16-S1-P94

Cite this article as: Smolinski et al: Analyzing adaptive modulation in spinal motor neurons using multi-objective evolutionary algorithms. BMC Neuroscience 2015 16(Suppl 1):P94.

\section{Submit your next manuscript to BioMed Central} and take full advantage of:

- Convenient online submission

- Thorough peer review

- No space constraints or color figure charges

- Immediate publication on acceptance

- Inclusion in PubMed, CAS, Scopus and Google Scholar

- Research which is freely available for redistribution

Submit your manuscript at www.biomedcentral.com/submit 